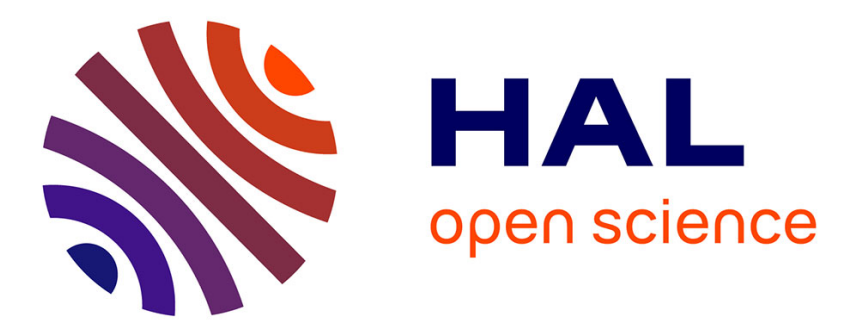

\title{
Costimulatory blockade molecules and B-cell-mediated immune response: current knowledge and perspectives
}

Claire Leibler, Allan Thiolat, Rebecca A. Elsner, Khalil El Karoui, Chloe Samson, Philippe Grimbert

\section{To cite this version:}

Claire Leibler, Allan Thiolat, Rebecca A. Elsner, Khalil El Karoui, Chloe Samson, et al.. Costimulatory blockade molecules and B-cell-mediated immune response: current knowledge and perspectives. Kidney International, 2019, 95, pp.774 - 786. 10.1016/j.kint.2018.10.028 . hal-03486907

\section{HAL Id: hal-03486907 https://hal.science/hal-03486907}

Submitted on 20 Dec 2021

HAL is a multi-disciplinary open access archive for the deposit and dissemination of scientific research documents, whether they are published or not. The documents may come from teaching and research institutions in France or abroad, or from public or private research centers.
L'archive ouverte pluridisciplinaire HAL, est destinée au dépôt et à la diffusion de documents scientifiques de niveau recherche, publiés ou non, émanant des établissements d'enseignement et de recherche français ou étrangers, des laboratoires publics ou privés.

\section{(ㄷ)(1) $\$$}

Distributed under a Creative Commons Attribution - NonCommerciall 4.0 International 
22 Service de Néphrologie et Transplantation

23 Pôle Cancérologie-Immunité-Transplantation-Infectiologie (CITI) et unité INSERM U955

24 CHU Henri Mondor and Université Paris-Est-Créteil (UPEC)

25 France

26 Tel: +33149812460/2453

27 Email: philippe.grimbert@aphp.fr

30 Running headline: Co-stimulatory molecules and B cell

\section{Co-stimulatory blockade molecules and B cell-mediated immune response : Current knowledge and perspectives}

${ }^{1}$ Service de Néphrologie et Transplantation, Pôle Cancérologie-Immunité-TransplantationInfectiologie (CITI) , '2Inserm, U955, Equipe 21 and Université Paris-Est (UPEC), Créteil, France, ${ }^{3}$ Department of Immunology, University of Pittsburgh School of Medicine, Pittsburgh, PA 15261, USA

CL and AT equally contributed to this work 


\section{Abstract}

34 There is an urgent need for therapeutic agents that target humoral alloimmunity in solid 35 organ transplantation. This includes sensitized patients with preformed donor-specific 36 human leukocyte antigen antibodies and patients who develop de-novo donor-specific 37 antibodies, both of which are associated with acute and chronic antibody-mediated 38 rejection and allograft loss. In the last decade both experimental and clinical studies

39 highlighted the major impact of co-stimulation molecules in the control of immune 40 responses both in the field of transplantation and autoimmune disease. Although these 41 molecules have been initially developed to control the early steps of $T$ cell activation, 42 recent evidence also supports their influence at several steps of the humoral response. In 43 this review we aim to provide an overview of the current knowledge of the effects of co44 stimulatory blockade agents on humoral responses in both autoimmune and allogeneic 45 contexts. We first present the effects of co-stimulatory molecules on the different steps of 46 alloantibody production. We then summarize mechanisms and clinical results observed 47 using CTLA4-Ig molecules both in transplantation and autoimmunity. Finally we present 48 the potential interest and implications of other co-stimulatory family members as 49 therapeutic targets, with emphasis on combinatorial approaches, for the optimal control of 50 the alloantigen-specific humoral response.

54 Keywords: acute rejection, lymphocytes 


\section{Introduction}

Antibody-mediated rejection (AMR) is now a well-recognized major contributor to

67 graft loss in kidney transplant recipients. It accounts for up to 2/3 of death-censored graft

68 failures beyond the first year of transplantation and is the leading cause of late transplant

69 failure ${ }^{1,2}$. AMR is likely to occur in sensitized kidney allograft recipients with anti-HLA 70 donor-specific antibodies (DSA) before and after transplantation ${ }^{3,4}$. Although our 71 understanding of the mechanisms behind DSA development is far from complete, 72 pathogenesis as well as clinical and histological features of DSA-mediated graft injury has 73 been more extensively analyzed during the last decade ${ }^{5}$. Indeed experimental studies 74 have shed light on the natural history of acute and chronic AMR ${ }^{6}$. The sequence starts with 75 the generation of antibodies directed against the graft. Although highly polymorphic 76 mismatched HLA molecules represent the most documented targets for DSA, it is clear 77 that DSA can also be directed against other kinds of molecular targets including 78 polymorphic minor histocompatibility antigens and, following a breakdown of $B$ cell 79 tolerance $^{7}$, non-polymorphic autoantigens ${ }^{8}$. Binding of circulating DSA to directly 80 accessible graft endothelial cells can trigger the activation of classical complement 81 pathway, a central process in the pathophysiology of acute $\mathrm{AMR}^{9}$. By contrast, the 82 pathogenesis of chronic AMR appears to be mainly related to antibody-dependent cell 83 mediated cytotoxicity $(A D C C)^{10}$. Binding of the FC fragment of DSA complexes to innate 84 immune cells causes their activation and inflammation, leading to smoldering endothelial 85 cell damage ${ }^{11}$. In turn, chronic vascular inflammation promotes the progressive 86 development of typical vascular lesions, i.e. transplant glomerulopathy, allograft 87 vasculopathy and lamination of the peritubular capillary basement membrane ${ }^{12}$.

88 Improving long-term graft survival by targeting various aspects of the humoral immune 89 response is a major goal in modern transplantation. To prevent both acute and chronic 90 AMR, de novo DSA synthesis needs to be prevented or limited. Currently, conventional 91 immunosupressive protocols involve a short-term induction therapy with Basilixumab or 92 Thymoglobulin, followed by a life-long maintenance immunosuppression combining 93 anticalcineurine, antiproliferative drugs such as MMF or mTor inhibitors and steroids. 
94 Although, these drugs target the different signaling pathways leading to alloantibody

95 production by $\mathrm{B}$ cells, around $15-30 \%$ of renal transplant recipients still develop de novo 96 DSA ${ }^{13-16}$. Therefore they are not effective enough to inhibit de novo DSA production and 97 new strategies need to be defined.

98 Additionally, currently up to $30-40 \%$ of transplant candidates are already sensitized, 99 limiting their donor options and putting them at a higher risk for AMR. Therefore 100 immunosuppressive protocols were tested to attempt to remove antibodies in sensitized 101 allograft patients to expand their chance of receiving a compatible transplant and 102 increasing graft survival ${ }^{17}$. These included numerous attempts to boost conventional 103 immunosuppression, or to inhibit/remove B cells, plasma cells, antibodies, and/or 104 complement ${ }^{18}$ through the use of $B$ cell depleting agents (e.g., rituximab and anti-CD20), 105 intravenous immunoglobulins, and plasmapheresis. Unfortunately, once DSAs are 106 established, no current therapies can reliably reverse their pathogenic effects: DSA titers 107 were incompletely reduced, and rebound of antibody production after treatment could be 108 observed leading to an overall increased risk of AMR and graft loss in some patients. 109 Moreover these controlled trials have used different treatment protocols, and have been 110 underpowered and of low quality ${ }^{19,20}$. These results strengthened the need to identify new 111 molecules and optimal immunosuppressive strategies to target humoral immune 112 responses.

113 Recent findings have highlighted the major impact of co-stimulation (co-stim) molecules for 114 the control of immune responses. Targeting the second signal of $T$ cell activation with co115 stim blockade to inhibit activation, or checkpoint inhibitors to increase it, has been a 116 revolutionary medical advance of the last decade. Unexpectedly, experimental data and 117 clinical studies suggested co-stim molecules also play a large role in controlling humoral 118 immune responses in both autoimmune and allogeneic settings. This review aims to 119 describe immune mechanisms leading to DSA production and how co-stim blockade can 120 modulate humoral immunity. We next consider clinical evidence for co-stim mediated 121 control of humoral immune responses in transplantation and autoimmune diseases with a 122 focus on the first clinically released drug, CTLA4-Ig. Finally, we discuss the potential 123 involvement of the individual family members and suggest original combinatory strategies 124 to optimally control allogenic humoral responses. 

molecules

\section{General mechanisms}

130 DSA are high affinity antibodies, typically IgG isotypes, mostly directed against donor HLA 131 molecules. These characteristics imply that DSA generation results from a $T$ cell-

132 dependent $B$ cell response. This type of humoral response, which primarily develops within 133 secondary lymphoid organs (spleen or lymph nodes), involves two distinct events that are 134 separated both spatially and temporally (Figure 1). Early events include, in parallel, the 135 activation/priming of allogeneic $\mathrm{T}$ cells by dendritic cells, and allogeneic $\mathrm{B}$ cells by the 136 antigen, in the secondary lymphoid organs (i.e. lymph nodes and spleen) ${ }^{21}$. Both activated

137 B and $\mathrm{T}$ cells then migrate to the border of $\mathrm{B}$ cell follicles and $\mathrm{T}$ cell zones, respectively, 138 where they undergo cognate interactions. These interactions lead to the development of 139 the germinal center (GC) response. GC B cells will cyclically increase their affinity to the 140 antigen and expand oligo-clonally ${ }^{22,23}$. At one point, memory $B$ cells and long lived plasma 141 cells will be generated, but the exact signals that stop GC cycle and drive one or the other 142 fate are unknown ${ }^{24}$.

\section{T follicular- B cell crosstalk}

$145 \mathrm{~T}$ follicular helper cells (Tfh) are now recognized to play a major role in the development of 146 humoral responses ${ }^{25-27}$. Tfh are $\mathrm{T}$ helper cells specialized in helping GC B cells through 147 cell-to-cell contact and the production of cytokines including IL-21. Their differentiation 148 requires the transcription factor Bcl6 and they can be defined by ICOS expression with 149 high CXCR5 and PD1 expression ${ }^{28}$. Experimental models and human studies suggest that 150 targeting Tfh, and particularly Tfh-B cell crosstalk, might be fundamental to control de novo 151 humoral immune responses in transplantation. In several non-human primate (NHP) 152 models, Kwun et al showed that GC size and frequency were positively correlated with 153 DSA production and incidence of humoral rejection ${ }^{29,30}$. Studies of Tfh-B cell crosstalk are

154 limited in humans due to the difficulties to access human lymph nodes ${ }^{31,32}$. Circulating 155 blood subsets of "Tfh" were identified" ${ }^{33}$. They share some, but not all, phenotypic 
156 characteristics with lymph node Tfh. These cells were found to express CXCR5, ICOS and

157 PD-1 but to a lower level than lymph node Tfh, and don't express the transcription factor $158 \mathrm{Bcl}-6$, known to be required for Tfh formation (in mice and humans ${ }^{34}$ ). They can also 159 interact with B cells, secrete IL-21 ex vivo, and induce plasmablasts differentiation and 160 antibody secretion in vitro. The origins and role of this $T$ cell population are still debated, 161 and whether they can directly reflect ongoing follicular Tfh-B cell interactions remains to be

162 fully determined. However, increased proportions of these circulating "Tfh-like" subsets 163 were shown to precede seroconversion in human vaccination studies ${ }^{35}$. S. Brouard's team 164 recently showed that following kidney transplant, increased blood Th frequency preceded 165 HLA sensitization in CNI-treated patients ${ }^{36}$. Conversely, operational tolerant recipients, a 166 unique and rare clinical situation in which kidney graft function is preserved without 167 immunosuppression, displayed lower DSA incidence, lower frequencies, and lower 168 functional ability of circulating Tfh compared to control graft patients.

169 Interestingly, two of the main markers used to identify and characterize Tfh functions, 170 ICOS and PD-1, belong to the co-stim molecule family. ICOS is known to be critical for Tfh 171 formation in mice ${ }^{37}$, and PD-1 was found to regulate the functional capacity of human 172 blood $\mathrm{Tfh}^{38}$. This highlights that a better understanding of the function of co-stim molecules 173 on human Tfh and their role in Tfh-B cell crosstalk may be crucial for future therapies.

Role of co-stimulatory molecules in Tfh generation, Tfh-B cell crosstalk and B cell responses

- Family of co-stimulatory molecules

179 Co-stim molecules have historically been shown to be fundamental for $\mathrm{T}$ cell priming by 180 DC. They are a complex set of stimulatory and inhibitory molecules, responsible for the 181 fine-tuning of $T$ cell activation ${ }^{39-41}$. After antigen recognition and engagement of the TCR, 182 the interaction of APC co-stim molecules with their ligands on T cells provides the 183 additional signal required to fully achieve T cell activation. CD40 on APC binds to its T cell 184 ligand CD40L resulting in the up-regulation of B7 molecules (CD80/CD86) and other co185 stim molecules on $\mathrm{APC}^{42}$. CD28, which is constitutively expressed on T cells, then binds to 
186 its ligands CD80 and CD86 on APC leading to T cell activation. Co-stim pathways also

187 trigger the expression of inhibitory receptors that are responsible for turning off or shutting 188 down the system to prevent uncontrolled activation. The inhibitory receptors share the 189 same ligands as their stimulatory counterparts and thus the competition for ligands is a 190 further mechanism of fine tuning $T$ cell activation. For example, the inhibitory receptor 191 CTLA4 is induced upon T cell activation, and binds to the B7 molecules CD80 and CD86 192 on APC with higher affinity than CD28. Thus its expression prevents further stimulatory 193 CD28-ligation from the APC (T cell-extrinsically), and produces a T cell intrinsic inhibitory 194 signal.

- Role of co-stim molecules in Tfh generation and function

198 It has recently been proven that co-stim molecules also play an important role in the 199 different steps of Tfh differentiation and function (Figure 2A). Due to their complexity and 200 involvement at different stages of this process (Figure 2B), the use of genetically deficient 201 animal models was crucial to demonstrate their functions.

203 ICOS, a critical mediator of Tfh cell generation and function.

204 ICOS plays an important role at each stage of Tfh development and function. At an early 205 stage, after DC priming, ICOS/COS-L interactions participates in the up-regulation of EBi2 206 leading to development of Tfh precursors ${ }^{43}$. Further chemokine receptor changes allow 207 them to migrate to the B cell follicle border $28,37,44$. Interactions between ICOS on Tfh and 208 ICOS-L on bystander B cells induce the activation of the PI3 kinase pathway, essential for 209 Tfh localization in the $\mathrm{GC}^{45}$. There, B cells offer repeated antigen presentation and co210 stimulation through ICOS to promote full development of Tfh cells by inducing expression 211 of the transcription factor $\mathrm{BcI}^{37}$. ICOS may also play a role in Tfh differentiation or survival 212 by regulating the induction of the transcription factor C-Maf, potentially through expression 213 of IL- $21^{46,47}$. In the GC, ICOS-L is responsible for the entanglement between Tfh and GC B 214 cells, a crucial feature to select $B$ cell clones with the highest affinity for the antigen ${ }^{48}$. 215 Therefore, in mice ICOS plays an important role in multiple stages of humoral immunity. 
216 Accordingly in humans, patients with ICOS deficiency have severely damaged GC and 217 reduced blood $\mathrm{CXCR}^{+} \mathrm{CD}^{2} 5 \mathrm{RO}^{+}$memory cells. Therefore, ICOS signaling is also likely to 218 play a fundamental role for Tfh differentiation in humans ${ }^{49}$.

$P D-1$, a complex role in Tfh function

221 PD-1 is another key marker that defines Tfh phenotype. On "non-Tfh" T cells, PD-1 is a 222 marker of exhaustion. PD-1 signaling down-regulates the activation of effector T cells by 223 dampening CD28 signaling ${ }^{50,51}$. However, the precise role of PD-1 in Tfh homeostasis and 224 function is more complex. Good-Jacobson et al showed that PD-1 deficient mice displayed 225 increased number of Th with decreased abilities to secrete cytokines (IL4 and IL21). On 226 the B cell side, PD-1-deficient mice had increased GC B cell mortality, decreased number 227 of plasma cells (PC) and overall decreased immunoglobulin production. However the 228 remaining PC produced higher affinity antibodies than PD-1-sufficient mice ${ }^{52}$. Recently, 229 Shi et al studied why PD-1 represses Tfh formation while it is also highly expressed on 230 Tfh. They found that PD-1 signaling helps to restrain Tfh in the GC by repressing CXCR3 231 expression that would distract Tfh and potentially allow them to migrate out of the $\mathrm{GC}^{53}$. 232 Thus PD-1 functions in Tfh formation and GC localization.

CD28-CTLA4, additional players in regulating Tfh differentiation

235 The role of CD28 for T cell activation has been known for a long time. Recently it is also 236 has been found that continuous CD28 expression is required for Tfh differentiation ${ }^{54}$. Along 237 parallel lines, CTLA4, the inhibitory competitor of CD28, restrains Tfh responses and 238 inhibits their B cell stimulatory function. Specifically, deletion of CTLA4 on Tfh increased 239 GC B cells and serum Ab titers ${ }^{55,56}$. - B cell intrinsic role of co-stimulatory molecules

242 Co-stim molecules also play a role in regulating B cell responses directly. CD40 signaling 243 in B cells, triggered by its interaction with CD40L on Tfh, is a well-known example of a co244 stim pathway directly influencing $B$ cell fate by a cell-intrinsic mechanism. The combinatory 
245 signals of CD40 and IL-21 in activated B cells induce the expression of Bcl6, a major 246 transcription factor required in GC B cells ${ }^{57}$. In GC B cells, Luo et al recently showed that 247 CD40 ligation in conjunction with BCR signaling was required to induce c-Myc, a major 248 transcription factor for GC B cell maintenance and survival ${ }^{58}$. Moreover, it was 249 demonstrated that CD40 was required on B cells intrinsically in the generation of antigen250 specific GC B cells, high-affinity class-switched antibody production, and also for antigen251 specific Tfh formation, suggesting that CD40-CD40L signaling is also bi-directional ${ }^{59-61}$. 252 Furthermore, CD40 signaling intrinsically regulates B cell homeostatic maintenance ${ }^{62}$. In 253 contrast to GC B cells, CD40 ligation alone is sufficient to activate naïve B cells in vitro.

254 Although CD28-CTLA4/CD80-CD86 pathway has been thought to mainly control T cell 255 activation, recent evidence suggest that they might also play a direct role on $B$ cells. Both 256 long-lived plasma cells (PC), that survive in the bone marrow and participate in sustaining 257 long-term antibody levels, and short-lived plasma cells, re-express CD28 in mice and 258 humans $^{63}$, due to the loss of the $\mathrm{B}$ cell master regulator Pax5 during terminal 259 differentiation ${ }^{64}$. Two teams have independently shown a role for CD28 in plasma cell 260 function. However its exact function is still debated. Rozanski et al showed that specific 261 CD28 deficiency in the B cell lineage was sufficient to decrease antigen-specific (NIP) IgG 262 titers by 10 -fold after immunization, even with adequate $T$ cell help ${ }^{65}$. They further showed 263 a PC-intrinsic function of CD28 that supports the survival of long-lived PC in the bone 264 marrow leading to increase $A b$ titers $^{65}$ through a Blimp-1 dependent mechanism ${ }^{66}$. 265 However, Njau et al found increased frequencies of PC and Ab production in CD28 266 deficient $\mathrm{PC}^{67}$.

267 The current evidence supports that targeting co-stim molecules likely acts both on the T 268 cells as well as on B cells (including plasma cells) to modulate the Tfh-B cell 269 crosstalk. Thus, further development of strategies targeting these molecules will be 270 important to further our ability to modulate humoral responses. 
275 Drugs targeting co-stim receptors have been developed in the past two decades to prevent 276 T cell mediated allograft rejection, or to control the activation of autoreactive $T$ cells in 277 autoimmune settings (Figure 3). A thorough compilation of the relevant co-stim molecules, 278 drugs which target them, and clinical trials can be found in Table 1. CD28/CTLA4/B7 axis 279 was the first pathway to be therapeutically inhibited. The use of a recombinant CD28-Ig to 280 bind CD80/CD86 and block natural CD28 signaling was ineffective due to its low affinity for 281 its B7 ligands leading to the development of another recombinant protein: the CTLA4-Ig 282 (Abatacept $)^{41}$. This fusion protein comprises the extracellular domain of human CTLA-4, 283 which has a higher affinity for CD80 and CD86 than CD28 does, fused with a fragment of 284 the Fc portion of human IgG1, to increase its half-life. Because the majority of the first 285 experimental and clinical data are related to the use of CTLA4-Ig (Abatacept) and its 286 higher affinity version Belatacept (LEA29Y) ${ }^{68}$ in auto-immunity and transplantation, we will 287 focus first on what was learned from these studies.

288 Although Belatacept has been mainly developed to target DC-priming of $\mathrm{T}$ cells, pre289 clinical models have interestingly shown that the use of Belatacept inhibited humoral 290 responses in transplantation settings. Follicle size, GC proportion and IL-21 secretion were 291 decreased in Belatacept treated primate recipients suggesting a specific role of Belatacept 292 on Tfh-B cell crosstalk.

293 Anita Chong's studies further showed, in murine models, that delayed CTLA4-Ig could 294 inhibit on-going humoral response, even if priming of allogenic $T$ cells had already 295 occurred $^{69,70}$. Indeed, introduction of CTLA4-Ig treatment 14 days after sensitization 296 inhibited alloantibody production and collapsed GC responses. These results suggested 297 that CTLA4-Ig action on B cell stimulatory capacities were important, independently of $T$ 298 cell priming by DC. Recently, in a murine skin transplant model, Baddell et al showed that 299 Belatacept inhibited the function of adoptively transferred allogenic Tfh leading to 300 decreased sensitization ${ }^{71}$.

301 We further studied mechanisms underlying Belatacept action on humoral response in 302 humans $^{72}$. We showed that Belatacept inhibited Tfh-B cell crosstalk in vitro by decreasing 303 the proportion of activated PD1+ICOS + Tfh cells, decreasing Tfh proliferation, and 304 decreasing the differentiation of B cells into plasmablasts. We confirmed that Belatacept 305 treated kidney-graft recipients displayed lower frequencies of circulating Tfh and terminally 
306 differentiated $\mathrm{B}$ cells than control recipients, suggesting that Belatacept might also target

307 and inhibit Tfh-B cell crosstalk in vivo.

308 Previously, Belatacept was mainly thought to alter B cell responses by blocking $\mathrm{T}$ cell

309 priming. We unraveled an additional B cell intrinsic mechanism. We showed it could

310 directly inhibit the immunoglobulin production of activated $B$ cells in vitro, without any $T$ cell

311 intervention. The direct effect of Belatacept on B cells may imply a signaling through

312 CD86, which was interestingly highly expressed in plasmablasts. It induced STAT3

313 activation in stimulated $B$ cells but not the Akt/NFkB pathway, similar to CTLA4-lg

314 mediated reverse signaling described in $\mathrm{DC}^{73,74}$.

315 The current evidence supports that targeting co-stim molecules likely acts both on the T 316 cells as well as on B cells (including plasma cells) to modulate the Tfh-B cell 317 crosstalk. Thus, further development of strategies targeting these molecules will be 318 important to further our ability to modulate humoral responses.

Belatacept use in transplantation: one step toward a better control of humoral responses

322 Belatacept was initially developed as anticalcineurine sparing strategies to prevent their 323 nephrotoxicity. Phase II and III clinical studies, BENEFIT and BENEFIT-EXT, which 324 evaluated Belatacept efficiency in non-sensitized kidney graft recipients showed an 325 increase in (i) overall survival, (ii) in graft survival leading to a $43 \%$ reduction in the risk of 326 death or graft loss and (iii) an improved graft function when recipients were treated with 327 Belatacept as compared to anticalcineurine regimens ${ }^{75}$. Several hypotheses could be 328 drawn to explain this clinical efficiency ${ }^{76}$, including improved patient's compliance to 329 monthly-infused treatment and anticalcineurine sparing toxicity.

330 Importantly, these studies also highlighted that Belatacept-treated recipients had a drastic 331 reduction of DSA incidence. The cumulative rate for the development of DSA was $4.6 \%$ in 332 the Belatacept group versus $17.8 \%$ in the control group, 84 months after transplantation ${ }^{75}$.

333 The lower incidence of HLA sensitization may account for the decreased risk of humoral 334 rejection and clinical efficiency with Belatacept treatment.

335 Animal models also confirmed that Belatacept specifically inhibited humoral responses and

336 T-dependent antibody production. Belatacept inhibited anti-sheep red blood cell antibodies

337 secretion more efficiently than its predecessor Abatacept in a murine model ${ }^{68}$. 
338 Furthermore, in non-human primate kidney transplant model, Belatacept treatment was the 339 only treatment able to prevent DSA formation ${ }^{77}$, whereas combinatory treatment with anti340 CD3, tacrolimus (anticalcineurine) and alefacept (anti-CD2) were ineffective at preventing 341 DSA formation and AMR.

342 Overall, Belatacept effects on humoral responses led, for the first time, to improved clinical 343 results as compared to the reference therapy (anticalcineurine+mycophenolate 344 mofetil+corticosteroid) in non-sensitized kidney recipients that led to its US FDA approval 345 in 2011. To more specifically inhibit CD28-mediated stimulatory pathway, while leaving 346 CTLA-4 inhibitory signaling intact (especially on Tfh), a new generation of CD28 blockade 347 agents was engineered: a pegylated Fab' antibody fragment antagonist of CD28, CD28-FC 348 (FR104) ${ }^{78-80}$. In a non-human primate transplantation model, CD28-Fc seems to have an 349 even more potent effect in controlling Tfh-B cell crosstalk than Belatacept ${ }^{81}$ : IL21 gene 350 expression was decreased in FR104 treated animal biopsies at 1 month. FR104 also 351 inhibited Tfh proliferation more potently than Belatacept in an in vitro model of Tfh-B cell 352 co-culture. In a murine skin transplant model, anti-CD28 led to superior inhibition of donor

353 targeted Tfh, GC B cells and DSA production than CTLA4- $\lg ^{71}$. Also promising, evaluation 354 of its effects in human transplantation settings is warranted.

\section{CTLA4-Ig in autoimmune disease}

Though the previously described therapies were initially designed to target $T$ 359 cells, in light of their newly recognized effects on humoral responses, it is important to 360 reconsider their mechanism of action in autoimmune diseases. Whereas generation of 361 DSA is the driving process of AMR pathogenesis, the precise roles of autoantibody in 362 the physiopathology of autoimmune diseases is still poorly understood. One reason for 363 this is that in transplantation settings, the source of the initial exposure to the antigens, 364 and the pathophysiological mechanisms of $T$ and $B$ cell mediated damage are known. 365 However, at the time of diagnosis of an autoimmune disease, the progression and 366 evolution of the immunological processes underlying it are unknown. Moreover, 367 "autoimmune diseases" refers to a variety of conditions with very different pathological 368 contexts and pathogenesis. 
Based on the finding that CD28 deficient mice were resistant to arthritis in a 370 model of collagen-induced arthritis $(\mathrm{CIA})^{82}$, targeting autoreactive T cells with CTLA4371 Ig demonstrated striking reduction of disease manifestations in lupus disease ${ }^{83}$, and $372 \mathrm{ClA}^{82}$ mouse models. According to the timing of administration, CTLA4-Ig 373 administration either prevented the development of CIA, or was able to ameliorate $374 \mathrm{CIA}^{82,84}$.

375 The promising pre-clinical results in murine models of lupus, especially for the 376 treatment of arthritis, spurred the initial human clinical trials of CTLA4-Ig. They mainly 377 focused on the treatment of patients with psoriasis ${ }^{85}$ and rheumatoid arthritis (RA). 378 Successful clinical trials with abatacept (human CTLA4-lg) led to abatacept approval 379 by the US Food and Drug Administration for the treatment of RA in $2005^{86}$. These trials 380 showed a reduction in autoantibody production, but it's unknown whether it is a direct 381 effect of CTLA4-Ig treatment on the humoral response, or an indirect effect of reduced 382 disease. CTLA4-Ig has been reported to inhibit antibody responses in humans in the 383 context of autoimmunity. Antibody titers induced after vaccination with the monovalent 384 pandemic 2009 influenza A H1N1 virus vaccine was severely reduced in abatacept385 treated rheumatoid patients as compared to control patients treated with Methotrexate $386(9 \% \text { versus } 58 \%)^{87}$.

Using the NZB/NZW.F1 experimental murine model of Systemic Lupus 388 Erythematous (SLE), it was observed that administration of murine CTLA4-Ig 389 prolonged survival and prevented autoantibody production ${ }^{83}$. However, clinical trials of 390 abatacept in SLE patients have not shown any clear efficacy ${ }^{88}$. In lupus nephritis, 391 abatacept did not clearly improve the outcome, despite some evidence of biological 392 activity, including decreased anti-double-stranded DNA antibody, C3, and C4 levels, 393 but the results were inconsistent ${ }^{89-91}$. Collectively, a more thorough understanding of 394 both the pathophysiology of individual autoimmune diseases, and the precise 395 mechanisms of function of abatacept is needed for a more targeted approach to 396 treatment. 


\section{Other co-stimulatory blockade agents}

402 Although CD28 was the first co-stim pathway to be therapeutically targeted, current 403 knowledge involving other co-stim pathways in T cell activation led to the development of 404 novel co-stim blockade agents. They have mainly been tested in animal models. We will 405 review their potential impact on humoral responses in light of recent advances of functional 406 mechanisms.

\section{$408 \quad C D 40 / C D 154$}

409 CD40/CD154 (CD40L) pathway seemed one of the most promising therapeutic targets in 410 pre-clinical murine and non-human primate models of transplantation. It belongs to the 411 TNF superfamily (Figure 2). As discussed in chapter 2, in contrast to other co-stim 412 pathways where the ligands on the APC mainly amplify $T$ cell activation signaling 413 pathways, activation of CD40 on B cells by CD40L is crucial for T cell dependent B cell 414 activation, and at several steps of their differentiation ${ }^{58}$. Consequently, the blockade of this 415 pathway has drastic consequences on humoral responses. In humans, the genetic 416 deficiency of CD40L leads to a severe immune disorder: hyper IgM syndrome. Patients 417 genetically deficient in CD40L are severely immune-compromised; they lack GC reactions 418 and produce decreased levels of class switched antibodies ${ }^{92-94}$, demonstrating the 419 importance of CD40/CD40L in immune responses.

420 In numerous experimental models of transplantation, inhibition of the CD40/CD40L 421 pathway led to remarkably increased graft survival ${ }^{95,96}$. Interestingly, using anti-CD154 422 (anti-CD40L) therapy has drastic consequence in reducing DSA production in mouse 423 models: treatment with anti-CD154 was able to terminate ongoing germinal center 424 reactions $^{69}$ and effectively reduced alloantibody production following renal transplantation 425 in rhesus macaques ${ }^{77}$. Finally, blocking this pathway is a potent means to induce 426 tolerance, i.e. stable graft function without any continuous immunosuppressive therapies, 427 in experimental models ${ }^{97}$.

428 However, human clinical trials evaluating the safety and efficiency of anti-CD154 reagents 429 had to be prematurely stopped due to severe thromboembolic complications, related to 
430 CD154 expression on human platelets ${ }^{98}$. Anti-human CD40, ASKP1240, has now been

431 developed as a safe and efficient alternative ${ }^{99,100}$.

432 Importantly, anti-CD40 is also very potent in controlling humoral responses. In non-human 433 primates, it inhibited the production of antibodies against tetanus toxoid (TT) in a dose434 dependent manner, with a complete inhibition of anti-TT IgG generation at the highest 435 dose ${ }^{100}$. These results suggest it also effectively blocks $G C$ and the production of high 436 affinity antibodies in this model. Moreover, production of DSA was abolished in ASKP1240 437 treated monkeys in a model of pancreatic islet transplantation ${ }^{99}$. ASKP1240 appears to be 438 a promising candidate for immunosuppression in clinical transplantation. Several clinical 439 trials in humans are on-going ${ }^{101,102}$.

\section{$P D-1 / P D-L 1$}

442 PD-1/PD-L1 is a major inhibitory pathway of T-cell activation. The use of PD-1 inhibitors to 443 boost $\mathrm{T}$ cell immunity has revolutionized the treatment and prognosis of several metastatic 444 cancers $^{103}$. As discussed in chapter1, Tfh cells express high levels of PD-1 but its function 445 on this specific T cell subset is complex. It dampens TCR and CD28 signaling and the 446 accumulation of Tfh. However it also influences Tfh migration and the stringency of B cells 447 affinity exiting the $\mathrm{GC}^{52,53}$. Therefore, in contrast to CTLA4-Ig, which mainly blocks $\mathrm{T}$ cells 448 from receiving co-stim signals, administering PDL1-lg is hypothesized to induce an 449 inhibitory signal through PD-1 on T cells. Since PDL1-lg is designed to mimic a stronger

450 PD-1 signal, it may also inadvertently increase the affinity of $B$ cells that effectively seed a 451 GC. PDL1-Ig efficacy to prevent organ rejection was studied in some experimental 452 models ${ }^{104,105}$. PDL1-lg, used in combination with anti-CD154, greatly increased organ 453 survival to 140 days versus 40 days and 13 days with the anti-CD154 or PDL1-Ig alone 454 respectively. Its impact on humoral response has not been assessed yet and will be 455 critical information.

$457 \quad I C O S / I C O S L$

458 ICOS-ICOS-L pathway is essential for Tfh differentiation, GC development, and 
459 maintenance ${ }^{37,48}$. However, robust antigen delivery by cognate B cells may overcome 460 ICOS-L requirement on B cells using compensatory signals ${ }^{106}$. Thus targeting ICOS-ICOS-

461 L pathway in autoimmunity or organ transplantation should be closely monitored.

462 To target this pathway, two therapeutic strategies have been developed and are in pre463 clinical studies; the use of recombinant ICOS-Ig protein, and the anti-ICOS blocking 464 antibody. ICOS-Ig was designed to out-compete binding of surface-bound ICOS on T cells 465 to its cognate receptor ICOS-L on APC, thus preventing the delivery of co-stim signal from 466 APC to T cells (Figure 2). ICOS-Ig was subsequently found to prevent the binding of 467 ICOS-L to CD28. Pre-clinical studies evaluating ICOS-Ig efficacy on preventing allograft 468 rejection produced disappointing results. In kidney transplanted non-human primates, the 469 use of ICOS-Ig alone as a short-term treatment did not modify overall survival as 470 compared to untreated animals ${ }^{107}$. Furthermore, co-administration of ICOS-Ig with 471 Belatacept did not improve graft survival as compared to Belatacept alone. More recently, 472 co-administration of ICOS-Ig with anti-CD40 also did not improve survival as compared to 473 anti-CD40 alone in a model of cardiac transplantation in non-human primates ${ }^{108}$.

474 The use of anti-ICOS, however, seemed to more effectively block humoral responses in 475 pre-clinical models. It led to a decreased production of DSA in a model of islet xeno476 transplantation ${ }^{109}$. Moreover, in combination with anti-CD40 in a model of chronic cardiac 477 humoral rejection, anti-ICOS led to decreased DSAs titer and ameliorated histology as 478 compared to anti-CD40 alone ${ }^{110}$. Hence anti-ICOS treatment may be a promising 479 candidate for clinical trials. It may be particularly effective when used in combinatory 480 therapies, as compensatory pathways may overrule its requirement. Optimal combinatory 481 therapies still need to be defined and tested in humans.

$484 \mathrm{~B} 7-\mathrm{H} 4$ is a new receptor of the B7 family, mainly expressed on B cells ${ }^{111}$, however its 485 ligand is unknown ${ }^{112}$. B7-H4 triggering on B cells in the context of EBV infection led to 486 increased expression of Fas-L inducing their apoptosis ${ }^{113}$ and reduced the proliferation of 487 EBV transformed lymphoma $\mathrm{B}$ cells ${ }^{114}$. B7-H4 also appeared to play a role in modulating 488 autoimmune disease. $\mathrm{B} 7-\mathrm{H} 4$ deficient lupus-prone mice have more severe disease and 
489 increased production of autoantibodies ${ }^{115}$. Inhibiting B7-H4 in a model of cardiac 490 transplantation increased DSA production without any influence on graft survival ${ }^{116}$. 491 Conversely injection of $\mathrm{B} 7-\mathrm{H} 4$ recombinant protein led to ameliorated disease in a lupus492 prone model ${ }^{115}$. Moreover in a murine pancreatic islet transplantation model, 493 overexpression of $\mathrm{B} 7-\mathrm{H} 4$ on donor cells led to increased graft survival and prolonged 494 euglycemia ${ }^{116-118}$. In both models, B7-H4 seems to interact and synergize with CD28495 CTLA4/B7 pathway: overexpression of B7-H4 increased CTLA4-lg mediated graft 496 survival ${ }^{118}$ and conversely blocking $\mathrm{B} 7-\mathrm{H} 4$ in CD28-deficient mice decreased graft 497 survival ${ }^{119}$. B7-H4 targeting may give interesting results when used in conjunction with 498 CTLA4-Ig/CD28-Fc regimen.

\section{$500 \quad C D 27 / C D 70$}

501 Compared to other TNFa family members, few studies have evaluated the impact of 502 targeting this pathway in transplantation. However it has been shown that CD27/CD70 503 plays a major role in $\mathrm{B}$ cell hematopoiesis and differentiation ${ }^{120}$. Indeed, CD27 is 504 expressed on early B cell progenitors ${ }^{121}$. In humans, CD27 is mainly known as a memory

505 B cell marker ${ }^{122}$. CD70 is transiently expressed on activated B cells but more permanently 506 on plasma cells ${ }^{123}$. Blocking CD70 signaling in vitro leads to decreased B cell activation 507 and immunoglobulin production ${ }^{124}$. CD70 pathway may also synergize with the CD40 508 pathway $^{124,125}$.

509 In experimental models, blocking CD70 led to increased-cardiac graft survival ${ }^{126}$. However 510 clinical efficacy relied on the use of a depleting antibody ${ }^{127}$. Another study suggested that 511 anti-CD27 therapy might efficiently control memory humoral responses in pre-sensitized 512 cardiac transplantation leading to increased graft survival ${ }^{128}$. Hence, targeting CD27/CD70 513 may lead to interesting results toward controlling humoral responses ${ }^{129}$.

\section{Future strategies}

517 Single agent-based therapy may not be sufficient to reach the ultimate goal of controlling 518 humoral responses that most likely rely on redundant mechanisms. Moreover, multiple 
519 barriers exist toward effectively targeting humoral responses. These include; (i) cellular

520 barriers and niches that prevent drug penetration, such as GC in secondary lymphoid 521 organs or plasmablast niches in bone marrow, (ii) the complementarity and redundancy of 522 certain pathways and (iii) potentially variable effects of the drugs at different stages of the 523 immune response, the basic mechanisms of which are still incompletely understood. Due 524 to these complexities, a combinatorial approach to co-stim blocking may be more effective, 525 and defining the best combinations is the ultimate goal.

\section{4.a. Combination of co-stimulatory blockades}

528 Co-stimulatory pathways are closely related ${ }^{39}$. For example, different ligands share the 529 same receptor (Figure 2) and signaling of a given pathway influences the others. Hui et al 530 recently showed that PD-L1-induced-signaling of PD-1 inhibited T cell activation through 531 CD28 signaling ${ }^{50}$. We also showed that using Belatacept modifies the expression of other 532 co-stim molecules, particularly PD-L1, in vitro ${ }^{72}$.

533 This implies that targeting one co-stim pathway may lead to the induction of a new 534 equilibrium of all co-stim molecule expression and function. These changes have to be 535 studied and taken into account when designing future therapeutic strategies.

536 With the use and development of new molecules directly targeting $B$ and plasma cells in 537 the autoimmune, transplantation, or hematological fields, the main challenge will be to 538 design the best complementary strategies (Figure 3).

\section{4.b. Costimulatory blockade agents and other B cell targeting therapies}

541 Bortezomib, a broad-spectrum proteasome inhibitor (PI), inhibits alloantibody production in 542 patients with kidney transplantation through induction of apoptosis in plasma cells ${ }^{130}$. In 543 the context of AMR, PI seems to reduce the titers of immunodominant DSA by $50 \%$, 544 especially for early $\mathrm{AMR}^{131}$. A similar, although transient, reduction rate has also been 545 observed for pre-formed anti-HLA antibodies in a prospective trial of PI-based 546 desensitization ${ }^{132}$. Interestingly, the authors also reported a low rate of de novo DSA 547 production (12.5\%) in the $43 \%$ of desensitized patients. In another study of 18 patients 
548 undergoing clonal deletion with donor-specific transfusion followed by treatment with 549 bortezomib, rATG, rituximab, and steroids, 4 patients developed de novo DSA, whereas 4 550 could be weaned off immunosuppression ${ }^{133}$. Similar results were reported in a small series 551 of pediatric heart transplant cases, where Bortezomib has been associated with a marked 552 reduction in de novo DSA and resolution of $\mathrm{AMR}^{134}$. More recently a randomized trial of 553 Bortezomib in late AMR failed to demonstrate that bortezomib could prevent glomerular 554 filtration rate loss, improve histologic or molecular disease features, or reduce DSA ${ }^{135}$. The 555 limited benefit of Bortezomib could be related to the nonselective nature of proteasome 556 inhibition. In a pre-clinical model, Kwun et al evaluated the combination of a proteasome 557 inhibitor (bortezomib) to deplete bone marrow PC, in conjunction with two co-stim 558 blockade agents (Belatacept and anti-CD40 (2C10)) to target GC, in a model of pre559 sensitized non-human primate kidney transplantation. This strategy increased allograft 560 survival and led to sustainable decreased DSA titers ${ }^{30}$. Hence targeting B cells at different 561 maturation stages might be useful.

562 Daratumumab binds with high affinity to human CD38 engaging diverse mechanisms of 563 action, including complement-dependent cytotoxicity, antibody-dependent cellular 564 cytotoxicity, antibody-dependent cellular phagocytosis, programmed cell death, modulation 565 of enzymatic activity, and immunomodulatory activity ${ }^{136}$. Daratumumab monotherapy 566 induced at least a partial response in around $30 \%$ of heavily pretreated and refractory 567 patients with multiple myeloma, with a favorable safety profile ${ }^{137}$. While CD38-targeting 568 antibodies were initially developed to kill malignant plasma cells, these monoclonal 569 antibodies may also abrogate the production of autoantibodies in autoimmune disorders. 570 Indeed, daratumumab was effective in the treatment of refractory autoimmune hemolytic 571 anemia. Similarly, daratumumab reduced total and allergen-specific lgE levels by depleting 572 IgE-producing plasma cells, and this suggests potential value of CD38 antibodies in the 573 management of severe allergy ${ }^{138}$.

574 Both drugs targeting terminally differentiated B cells and particularly plasma cells might be 575 particularly interesting to use in combination therapies when these cells play a detrimental 576 role: in the context of antibody-mediated rejection or in pre-sensitized patients. 
579 Another therapeutic possibility would be to combine co-stim blockade with cytokine 580 inhibitors. In this context we will consider the 3 major cytokines implied in B cell functions: 581 IL-21, BAFF and IL-6.

582 IL-21 is an important cytokine secreted by Tfh. It sustains terminally differentiated B cell 583 generation. Blocking the IL-21 pathway in conjunction with co-stim blockade might be an 584 efficient means to control humoral responses. In an in vitro model, in which lymphocytes of 585 the graft recipient are stimulated with donor antigens, blocking IL-21R led to a decrease in 586 plasmablasts differentiation ${ }^{139}$. In pre-clinical models of islet transplantation, infusion of 587 soluble IL-21R to neutralize IL-21, or the IL-21 blocking antibody, doubled CTLA4-Ig 588 mediated graft survival ${ }^{140}$.

589 The B cell-stimulating molecules, BAFF (B cell activating factor) and APRIL (a 590 proliferation-inducing ligand), are critical factors in the maintenance of the $B$ cell pool and 591 humoral immunity. BAFF and APRIL bind to transmembrane activator and CAML 592 interactor (TACI) and $B$ cell maturation antigen (BCMA), while BAFF additionally binds to a 593 third receptor, BAFF-R; all three receptors are expressed by $B$ lineage cells ${ }^{141}$. BAFF 594 maintains $B$ cell homeostasis by acting as a survival and fitness factor for $B$ cells from the 595 transitional stage of development onwards, while APRIL appears to act at a later stage, 596 modulating the function and survival of antigen-experienced $B$ cells ${ }^{142-145}$. BAFF is 597 elevated in various autoimmune diseases including SLE, rheumatoid arthritis (RA) and 598 Sjögren's syndrome, and BAFF elevation is associated with autoantibody production ${ }^{146}$. 599 Several therapeutics targeting BAFF as a treatment for autoimmune diseases have been 600 developed $^{147}$. FDA approved belimumab, a monoclonal anti-BAFF antibody, for the 601 treatment of SLE in 2011, and Atacicept, blisibimod, and tabalumab, a recombinant 602 soluble TACI receptor, and two selective antagonists of BAFF respectively are currently 603 being tested in phase III trials for the therapy of SLE.

604 Recently Kwun et al tested the ability of Atacicept to prevent alloantibody production and 605 prolong allograft survival ${ }^{29}$ after kidney transplantation in non-human primates. They 606 showed that Atacicept prevented early DSA formation and AMR development in an 607 induced AMR model, although more $T$ cell rejection findings were observed. Whether 
608 targeting BAFF/APRIL could be useful for prevention and/or treatment of AMR in humans 609 remain to be established.

610 IL-6 also plays a major role in B cell differentiation into plasma cells or memory B cells.

611 Moreover IL-6 is needed for the long-term survival of plasma cells ${ }^{148-150}$. Blocking IL- 6 with

612 Tocilizumab (anti IL-6R) seems to be an efficient method to block unwanted immune 613 responses in autoimmunity ${ }^{151,152}$, thus several studies have evaluated its role in the 614 prevention of graft rejection. Jordan et al recently reviewed the role of anti IL-6 therapy on 615 AMR in transplantation models ${ }^{149}$. Briefly, tociluzimab significantly reduced the risk of AMR 616 in pre-sensitized kidney transplant recipients ${ }^{153}$. However it was ineffective at treating 617 AMR. A new generation of IL-6 blocking agents, an anti-IL-6 blocking antibody 618 (NCT03380962), is being developed and tested. Several pre-clinical observations suggest 619 that the combined use of co-stim blockade with IL-6 blockade might be highly beneficial for 620 graft survival. In combination with co-stim blockade (anti-CD154 and CTLA4-lg), both 621 genetic deficiency in IL-6 and treatment with anti-IL-6 blocking antibodies led to increased 622 graft survival in multiple transplantation models ${ }^{154,155}$. This association must be better 623 understood and may improve transplant outcomes in humans but need to be evaluated.

\section{Conclusion}

627 Co-stimulatory molecules are now well-recognized therapeutic targets for controlling 628 immune activation. They are central to allo-and auto-reactive $T$ cell responses and thus 629 are viable targets for inhibiting graft rejection and auto-reactive $T$ cells. There are now 630 strong arguments that co-stimulation pathways may also play active roles in controlling the 631 pathways leading to DSA and autoantibody production. Both experimental models and 632 clinical data in solid organ transplantation indicate that CTLA4-Ig may uniquely control B 633 cell responses. It modulates both their stimulatory capacities, leading to the impairment of 634 Tfh-B cell crosstalk, and the production of antibodies by effector B cells. Other 635 costimulatory molecules including CD40/CD40-L, ICOS/ICOS-L, PD-1/PD-L1 are also 636 involved in Tfh function, Tfh-B cell crosstalk, and plasma cell homeostasis, and may be 637 promising therapeutic options.

638 Effective control of the humoral responses during transplantation may require targeting of 
639 both B cell APC function and antibody production. Now with the expansion of tools that 640 can target both functions, and the demonstration of increased effectiveness of combination 641 strategies, real improvement in graft survival may be within reach.

643 Disclosure

644 All the authors declared no competing interests

645

646

References

648

649

1. Sellarés J, de Freitas DG, Mengel M et al. Understanding the Causes of Kidney Transplant

650 Failure: The Dominant Role of Antibody-Mediated Rejection and Nonadherence:

651 Attributing Causes of Kidney Transplant Loss. American Journal of Transplantation 2012;

: 388-399.

652

653

2. Einecke G, Sis B, Reeve J et al. Antibody-mediated microcirculation injury is the major cause of late kidney transplant failure. Am. J. Transplant. 2009; 9: 2520-2531.

654 3. Lefaucheur C, Loupy A, Hill GS et al. Preexisting donor-specific HLA antibodies predict

655

656

657 outcome in kidney transplantation. J. Am. Soc. Nephrol. 2010; 21: 1398-1406.

658 4. Aubert O, Loupy A, Hidalgo L et al. Antibody-Mediated Rejection Due to Preexisting versus De Novo Donor-Specific Antibodies in Kidney Allograft Recipients. J. Am. Soc.

659 Nephrol. 2017; 28: 1912-1923.

660 5. Djamali A, Kaufman DB, Ellis TM et al. Diagnosis and management of antibody-mediated

661 rejection: current status and novel approaches. Am. J. Transplant. 2014; 14: 255-271.

662 6. Pouliquen E, Koenig A, Chen CC et al. Recent advances in renal transplantation:

663

664

665

666

667

668

669

670 antibody-mediated rejection takes center stage. F1000Prime Rep 2015; 7: 51.

7. Thaunat 0 , Graff-Dubois S, Fabien N et al. A stepwise breakdown of B-cell tolerance occurs within renal allografts during chronic rejection. Kidney Int. 2012; 81: 207-219. 8. Li L, Wadia P, Chen R et al. Identifying compartment-specific non-HLA targets after renal transplantation by integrating transcriptome and "antibodyome" measures. Proc. Natl. Acad. Sci. U.S.A. 2009; 106: 4148-4153.

9. Sicard A, Ducreux S, Rabeyrin M et al. Detection of C3d-binding donor-specific anti-HLA antibodies at diagnosis of humoral rejection predicts renal graft loss. J. Am. Soc. Nephrol.

2015; 26: 457-467.

671

672

673

674 10. Yuan FF, Watson N, Sullivan JS et al. Association of Fc gamma receptor IIA

675

676

677 polymorphisms with acute renal-allograft rejection. Transplantation 2004; 78: 766-769. 11. Smith RN, Colvin RB. Chronic alloantibody mediated rejection. Semin. Immunol. 2012; 24: 115-121.

678 12. Hirohashi T, Uehara S, Chase CM et al. Complement independent antibody-mediated endarteritis and transplant arteriopathy in mice. Am. J. Transplant. 2010; 10: 510-517. 13. Hidalgo LG, Campbell PM, Sis B et al. De novo donor-specific antibody at the time of 679 kidney transplant biopsy associates with microvascular pathology and late graft failure. Am. J. Transplant. 2009; 9: 2532-2541. 
680

681

682

683

684

685

686

687

688

689

690

691

692

693

694

695

696

697

698

699

700

701

702

703

704

705

706

707

708

709

710

711

712

713

714

715

716

717

718

719

720

721

722

723

724

725
14. Wiebe C, Gibson IW, Blydt-Hansen TD et al. Evolution and Clinical Pathologic

Correlations of De Novo Donor-Specific HLA Antibody Post Kidney Transplant: Clinical Pathologic Correlations of De Novo DSA. American Journal of Transplantation 2012; 12: 1157-1167.

15. Rostaing L, Kamar N. Can we prevent donor-specific antibodies from developing after ABO-incompatible kidney transplantation? Kidney Int. 2014; 85: 245-247.

16. Thaunat $\mathrm{O}$, Koenig A, Leibler C et al. Effect of Immunosuppressive Drugs on Humoral Allosensitization after Kidney Transplant. J. Am. Soc. Nephrol. 2016; 27: 1890-1900. 17. Süsal C, Opelz G. Transplantation: Desensitization and survival in kidney transplant recipients. Nat Rev Nephrol 2017; 13: 196-198.

18. Everly MJ, Terasaki PI. The state of therapy for removal of alloantibody producing plasma cells in transplantation. Semin. Immunol. 2012; 24: 143-147.

19. Roberts DM, Jiang SH, Chadban SJ. The treatment of acute antibody-mediated rejection in kidney transplant recipients-a systematic review. Transplantation 2012; 94: 775-783. 20. Wan SS, Ying TD, Wyburn K et al. The Treatment of Antibody-Mediated Rejection in Kidney Transplantation: An Updated Systematic Review and Meta-Analysis.

Transplantation 2018; 102: 557-568.

21. Kurosaki T, Kometani K, Ise W. Memory B cells. Nature Reviews Immunology 2015; 15: 149-159.

22. Allen CDC, Okada T, Cyster JG. Germinal-center organization and cellular dynamics. Immunity 2007; 27: 190-202.

23. Victora GD, Schwickert TA, Fooksman DR et al. Germinal center dynamics revealed by multiphoton microscopy with a photoactivatable fluorescent reporter. Cell 2010; 143: 592-605.

24. Shlomchik MJ, Weisel F. Germinal center selection and the development of memory B and plasma cells. Immunol. Rev. 2012; 247: 52-63.

25. Qi H. T follicular helper cells in space-time. Nat. Rev. Immunol. 2016; 16: 612-625.

26. Ueno H, Banchereau J, Vinuesa CG. Pathophysiology of T follicular helper cells in humans and mice. Nat Immunol 2015; 16: 142-152.

27. Vinuesa CG, Linterman MA, Yu D et al. Follicular Helper T Cells. Annu. Rev. Immunol. 2016; 34: 335-368.

28. Crotty S. T follicular helper cell differentiation, function, and roles in disease. Immunity 2014; 41: 529-542.

29. Kwun J, Page E, Hong JJ et al. Neutralizing BAFF/APRIL with atacicept prevents early DSA formation and AMR development in T cell depletion induced nonhuman primate AMR model. Am. J. Transplant. 2015; 15: 815-822.

30. Kwun J, Manook M, Page E et al. Crosstalk Between T and B Cells in the Germinal Center After Transplantation. Transplantation 2017; 101: 704-712.

31. Schroder PM, Ezekian B, Ford M et al. Commentary: Belatacept Does Not Inhibit Follicular T Cell-Dependent B-Cell Differentiation in Kidney Transplantation. Front Immunol 2017; 8: 1615.

32. Walters GD, Vinuesa CG. T Follicular Helper Cells in Transplantation. Transplantation 2016; 100: 1650-1655.

33. Morita R, Schmitt N, Bentebibel S-E et al. Human blood CXCR5(+)CD4(+) T cells are counterparts of $\mathrm{T}$ follicular cells and contain specific subsets that differentially support antibody secretion. Immunity 2011; 34: 108-121. 
726

727

728

729

730

731

732

733

734

735

736

737

738

739

740

741

742

743

744

745

746

747

748

749

750

751

752

753

754

755

756

757

758

759

760

761

762

763

764

765

766

767

768

769

770

771

34. Locci M, Havenar-Daughton C, Landais E et al. Human circulating PD-1+CXCR3CXCR5+ memory Tfh cells are highly functional and correlate with broadly neutralizing HIV antibody responses. Immunity 2013; 39: 758-769.

35. Bentebibel S-E, Lopez S, Obermoser G et al. Induction of ICOS+CXCR3+CXCR5+ TH cells correlates with antibody responses to influenza vaccination. Sci Transl Med 2013; 5: 176 ra32.

36. Chenouard A, Chesneau M, Bui Nguyen L et al. Renal operational tolerance is associated with a defect of blood Tfh cells that exhibit impaired B cell help. Am. J. Transplant. 2016.

37. Choi YS, Kageyama R, Eto D et al. ICOS receptor instructs T follicular helper cell versus effector cell differentiation via induction of the transcriptional repressor Bcl6. Immunity 2011; 34: 932-946.

38. Sage PT, Francisco LM, Carman CV et al. The receptor PD-1 controls follicular regulatory T cells in the lymph nodes and blood. Nat. Immunol. 2013; 14: 152-161.

39. Ford ML. T Cell Cosignaling Molecules in Transplantation. Immunity 2016; 44: 10201033.

40. Schildberg FA, Klein SR, Freeman GJ et al. Coinhibitory Pathways in the B7-CD28 Ligand-Receptor Family. Immunity 2016; 44: 955-972.

41. Esensten JH, Helou YA, Chopra G et al. CD28 Costimulation: From Mechanism to Therapy. Immunity 2016; 44: 973-988.

42. Mueller DL, Jenkins MK, Schwartz RH. Clonal expansion versus functional clonal inactivation: a costimulatory signalling pathway determines the outcome of $\mathrm{T}$ cell antigen receptor occupancy. Annu. Rev. Immunol. 1989; 7: 445-480.

43. Li J, Lu E, Yi T et al. EBI2 augments Tfh cell fate by promoting interaction with IL-2quenching dendritic cells. Nature 2016; 533: 110-114.

44. Haynes NM, Allen CDC, Lesley R et al. Role of CXCR5 and CCR7 in follicular Th cell positioning and appearance of a programmed cell death gene-1high germinal centerassociated subpopulation. J. Immunol. 2007; 179: 5099-5108.

45. Xu H, Li X, Liu D et al. Follicular T-helper cell recruitment governed by bystander B cells and ICOS-driven motility. Nature 2013; 496: 523-527.

46. Bauquet AT, Jin H, Paterson AM et al. The costimulatory molecule ICOS regulates the expression of c-Maf and IL-21 in the development of follicular T helper cells and TH-17 cells. Nat. Immunol. 2009; 10: 167-175.

47. Kroenke MA, Eto D, Locci M et al. Bcl6 and Maf cooperate to instruct human follicular helper CD4 T cell differentiation. J. Immunol. 2012; 188: 3734-3744.

48. Liu D, Xu H, Shih C et al. T-B-cell entanglement and ICOSL-driven feed-forward regulation of germinal centre reaction. Nature 2015; 517: 214-218.

49. Bossaller L, Burger J, Draeger R et al. ICOS deficiency is associated with a severe reduction of CXCR5+CD4 germinal center Th cells. J. Immunol. 2006; 177: 4927-4932. 50. Hui E, Cheung J, Zhu J et al. T cell costimulatory receptor CD28 is a primary target for PD-1-mediated inhibition. Science 2017.

51. Kamphorst AO, Wieland A, Nasti T et al. Rescue of exhausted CD8 T cells by PD-1targeted therapies is CD28-dependent. Science 2017.

52. Good-Jacobson KL, Szumilas CG, Chen L et al. PD-1 regulates germinal center B cell survival and the formation and affinity of long-lived plasma cells. Nat. Immunol. 2010; 11: 535-542. 
772

773

774

775

776

777

778

779

780

781

782

783

784

785

786

787

788

789

790

791

792

793

794

795

796

797

798

799

800

801

802

803

804

805

806

807

808

809

810

811

812

813

814

815

816

817

53. Shi J, Hou S, Fang Q et al. PD-1 Controls Follicular T Helper Cell Positioning and Function. Immunity 2018; 49: 264-274.e4.

54. Linterman MA, Denton AE, Divekar DP et al. CD28 expression is required after T cell priming for helper $\mathrm{T}$ cell responses and protective immunity to infection. Elife 2014; 3. 55. Sage PT, Paterson AM, Lovitch SB et al. The coinhibitory receptor CTLA-4 controls B cell responses by modulating $\mathrm{T}$ follicular helper, $\mathrm{T}$ follicular regulatory, and $\mathrm{T}$ regulatory cells. Immunity 2014; 41: 1026-1039.

56. Wang CJ, Heuts F, Ovcinnikovs V et al. CTLA-4 controls follicular helper T-cell differentiation by regulating the strength of CD28 engagement. Proc. Natl. Acad. Sci. U.S.A. 2015; 112: 524-529.

57. Linterman MA, Beaton L, Yu D et al. IL-21 acts directly on B cells to regulate Bcl-6 expression and germinal center responses. J. Exp. Med. 2010; 207: 353-363.

58. Luo W, Weisel F, Shlomchik MJ. B Cell Receptor and CD40 Signaling Are Rewired for Synergistic Induction of the c-Myc Transcription Factor in Germinal Center B Cells.

Immunity 2018; 48: 313-326.e5.

59. Watanabe M, Fujihara C, Radtke AJ et al. Co-stimulatory function in primary germinal center responses: CD40 and B7 are required on distinct antigen-presenting cells. J. Exp. Med. 2017; 214: 2795-2810.

60. Lumsden JM, Williams JA, Hodes RJ. Differential requirements for expression of CD80/86 and CD40 on B cells for T-dependent antibody responses in vivo. J. Immunol. 2003; 170: 781-787.

61. Lee BO, Moyron-Quiroz J, Rangel-Moreno J et al. CD40, but not CD154, expression on B cells is necessary for optimal primary B cell responses. J. Immunol. 2003; 171: 57075717.

62. Schwartz MA, Kolhatkar NS, Thouvenel C et al. CD4+ T Cells and CD40 Participate in Selection and Homeostasis of Peripheral B Cells. The Journal of Immunology 2014; 193: 3492-3502.

63. Bahlis NJ, King AM, Kolonias D et al. CD28-mediated regulation of multiple myeloma cell proliferation and survival. Blood 2007; 109: 5002-5010.

64. Delogu A, Schebesta A, Sun Q et al. Gene repression by Pax5 in B cells is essential for blood cell homeostasis and is reversed in plasma cells. Immunity 2006; 24: 269-281. 65. Rozanski CH, Arens R, Carlson LM et al. Sustained antibody responses depend on CD28 function in bone marrow-resident plasma cells. J. Exp. Med. 2011; 208: 1435-1446. 66. Rozanski CH, Utley A, Carlson LM et al. CD28 Promotes Plasma Cell Survival, Sustained Antibody Responses, and BLIMP-1 Upregulation through Its Distal PYAP Proline Motif. J. Immunol. 2015; 194: 4717-4728.

67. Njau MN, Kim JH, Chappell CP et al. CD28-B7 interaction modulates short- and longlived plasma cell function. J. Immunol. 2012; 189: 2758-2767.

68. Larsen CP, Pearson TC, Adams AB et al. Rational development of LEA29Y (belatacept), a high-affinity variant of CTLA4-Ig with potent immunosuppressive properties. Am. J. Transplant. 2005; 5: 443-453.

69. Chen J, Yin $\mathrm{H}, \mathrm{Xu}$ J et al. Reversing endogenous alloreactive B cell GC responses with anti-CD154 or CTLA-4Ig. Am. J. Transplant. 2013; 13: 2280-2292.

70. Young JS, Chen J, Miller ML et al. Delayed CTLA4-Ig treatment reverses ongoing alloantibody responses and rescues allografts from acute rejection. Am. J. Transplant. 2016. 
818

819

820

821

822

823

824

825

826

827

828

829

830

831

832

833

834

835

836

837

838

839

840

841

842

843

844

845

846

847

848

849

850

851

852

853

854

855

856

857

858

859

860

861

862

863
71. Badell IR, La Muraglia GM, Liu D et al. Selective CD28 Blockade Results in Superior Inhibition of Donor-Specific T Follicular Helper Cell and Antibody Responses Relative to CTLA4-Ig. Am. J. Transplant. 2018; 18: 89-101.

72. Leibler C, Thiolat A, Hénique $C$ et al. Control of Humoral Response in Renal

Transplantation by Belatacept Depends on a Direct Effect on B Cells and Impaired T Follicular Helper-B Cell Crosstalk. J. Am. Soc. Nephrol. 2018; 29: 1049-1062.

73. Kowalczyk A, D'Souza CA, Zhang L. Cell-extrinsic CTLA4-mediated regulation of dendritic cell maturation depends on STAT3. Eur. J. Immunol. 2014; 44: 1143-1155. 74. Koorella C, Nair JR, Murray ME et al. Novel regulation of CD80/CD86-induced phosphatidylinositol 3-kinase signaling by NOTCH1 protein in interleukin- 6 and indoleamine 2,3-dioxygenase production by dendritic cells. J. Biol. Chem. 2014; 289: 7747-7762.

75. Vincenti F, Rostaing L, Grinyo J et al. Belatacept and Long-Term Outcomes in Kidney Transplantation. N. Engl. J. Med. 2016; 374: 333-343.

76. Heher E, Markmann JF. The Clearer BENEFITS of Belatacept. N. Engl. J. Med. 2016; 374: 388-389.

77. Kim EJ, Kwun J, Gibby AC et al. Costimulation blockade alters germinal center responses and prevents antibody-mediated rejection. Am J Transplant 2014; 14: 59-69. 78. Poirier N, Blancho G, Vanhove B. CD28-specific immunomodulating antibodies: what can be learned from experimental models? Am. J. Transplant. 2012; 12: 1682-1690. 79. Poirier N, Dilek N, Mary C et al. FR104, an antagonist anti-CD28 monovalent fab' antibody, prevents alloimmunization and allows calcineurin inhibitor minimization in nonhuman primate renal allograft. Am. J. Transplant. 2015; 15: 88-100.

80. Poirier N, Chevalier M, Mary C et al. Selective CD28 Antagonist Blunts Memory Immune Responses and Promotes Long-Term Control of Skin Inflammation in Nonhuman Primates. J. Immunol. 2016; 196: 274-283.

81. Ville S, Poirier N, Branchereau J et al. Anti-CD28 Antibody and Belatacept Exert Differential Effects on Mechanisms of Renal Allograft Rejection. J. Am. Soc. Nephrol. 2016. 82. Knoerzer DB, Karr RW, Schwartz BD et al. Collagen-induced arthritis in the BB rat. Prevention of disease by treatment with CTLA-4-Ig. J. Clin. Invest. 1995; 96: 987-993. 83. Finck BK, Linsley PS, Wofsy D. Treatment of murine lupus with CTLA4Ig. Science 1994; 265: $1225-1227$.

84. Webb LM, Walmsley MJ, Feldmann M. Prevention and amelioration of collageninduced arthritis by blockade of the CD28 co-stimulatory pathway: requirement for both B7-1 and B7-2. Eur. J. Immunol. 1996; 26: 2320-2328.

85. Abrams JR, Lebwohl MG, Guzzo CA et al. CTLA4Ig-mediated blockade of T-cell costimulation in patients with psoriasis vulgaris. J. Clin. Invest. 1999; 103: 1243-1252. 86. Ford ML, Adams AB, Pearson TC. Targeting co-stimulatory pathways: transplantation and autoimmunity. Nat Rev Nephrol 2014; 10: 14-24.

87. Ribeiro AC, Laurindo IM, Guedes LK et al. Abatacept and reduced immune response to pandemic 2009 influenza A/H1N1 vaccination in patients with rheumatoid arthritis. Arthritis Care Res (Hoboken) 2013; 65: 476-480.

88. Merrill JT, Burgos-Vargas R, Westhovens R et al. The efficacy and safety of abatacept in patients with non-life-threatening manifestations of systemic lupus erythematosus: results of a twelve-month, multicenter, exploratory, phase IIb, randomized, double-blind, placebo-controlled trial. Arthritis Rheum. 2010; 62: 3077-3087. 
864 89. Wofsy D, Hillson JL, Diamond B. Comparison of alternative primary outcome measures 865 for use in lupus nephritis clinical trials. Arthritis Rheum. 2013; 65: 1586-1591.

866 90. ACCESS Trial Group. Treatment of lupus nephritis with abatacept: the Abatacept and

867 Cyclophosphamide Combination Efficacy and Safety Study. Arthritis \& Rheumatology

868 (Hoboken, N.J.) 2014; 66: 3096-3104.

869 91. Furie R, Nicholls K, Cheng T-T et al. Efficacy and safety of abatacept in lupus nephritis:

870 a twelve-month, randomized, double-blind study. Arthritis \& Rheumatology (Hoboken, N.J.)

$8712014 ; 66: 379-389$.

872 92. Allen RC, Armitage RJ, Conley ME et al. CD40 ligand gene defects responsible for X-

873 linked hyper-IgM syndrome. Science 1993; 259: 990-993.

874 93. DiSanto JP, Bonnefoy JY, Gauchat JF et al. CD40 ligand mutations in $\mathrm{x}$-linked

875 immunodeficiency with hyper-IgM. Nature 1993; 361: 541-543.

876

877

94. Korthäuer U, Graf D, Mages HW et al. Defective expression of T-cell CD40 ligand causes

X-linked immunodeficiency with hyper-IgM. Nature 1993; 361: 539-541.

878

879

880

95. Kirk AD, Burkly LC, Batty DS et al. Treatment with humanized monoclonal antibody

against CD154 prevents acute renal allograft rejection in nonhuman primates. Nat. Med.

1999; 5: 686-693.

881

882

96. Elgueta R, Benson MJ, de Vries VC et al. Molecular mechanism and function of

883

884

CD40/CD40L engagement in the immune system. Immunol. Rev. 2009; 229: 152-172.

97. Pinelli DF, Ford ML. Novel insights into anti-CD40/CD154 immunotherapy in

transplant tolerance. Immunotherapy 2015; 7: 399-410.

885

886

887

888

98. Kawai T, Andrews D, Colvin RB et al. Thromboembolic complications after treatment

with monoclonal antibody against CD40 ligand. Nat. Med. 2000; 6: 114.

99. Watanabe M, Yamashita K, Suzuki T et al. ASKP1240, a fully human anti-CD40

889

monoclonal antibody, prolongs pancreatic islet allograft survival in nonhuman primates.

Am. J. Transplant. 2013; 13: 1976-1988.

890

891

892

100. Okimura K, Maeta K, Kobayashi N et al. Characterization of ASKP1240, a fully human

antibody targeting human CD40 with potent immunosuppressive effects. Am. J.

Transplant. 2014; 14: 1290-1299.

893

894

895

101. Goldwater R, Keirns J, Blahunka P et al. A phase 1, randomized ascending single-dose study of antagonist anti-human CD40 ASKP1240 in healthy subjects. Am. J. Transplant. 2013; 13: 1040-1046.

896

897

102. Rostaing L, Malvezzi P. Costimulation Blockade in Kidney Transplantation: Beyond

898

899

Belatacept. Transplantation 2016; 100: 2516-2518.

103. Pardoll DM. The blockade of immune checkpoints in cancer immunotherapy. Nat.

900

Rev. Cancer 2012; 12: 252-264.

901

104. Gao W, Demirci G, Strom TB et al. Stimulating PD-1-negative signals concurrent with

902 blocking CD154 co-stimulation induces long-term islet allograft survival. Transplantation

903 105. Dudler J, Li J, Pagnotta M et al. Gene transfer of programmed death ligand-1.Ig

904

905

906

907

908

909 prolongs cardiac allograft survival. Transplantation 2006; 82: 1733-1737.

106. Weinstein JS, Bertino SA, Hernandez SG et al. B cells in T follicular helper cell development and function: separable roles in delivery of ICOS ligand and antigen. J. Immunol. 2014; 192: 3166-3179.

107. Lo DJ, Anderson DJ, Song M et al. A pilot trial targeting the ICOS-ICOS-L pathway in nonhuman primate kidney transplantation. Am. J. Transplant. 2015; 15: 984-992. 
910

911

912

913

914

915

916

917

918

919

920

921

922

923

924

925

926

927

928

929

930

931

932

933

934

935

936

937

938

939

940

941

942

943

944

945

946

947

948

949

950

951

952

953

954

955
108. O'Neill NA, Zhang T, Braileanu G et al. Pilot Study of Delayed ICOS/ICOS-L Blockade With $\alpha \mathrm{CD} 40$ to Modulate Pathogenic Alloimmunity in a Primate Cardiac Allograft Model. Transplant Direct 2018; 4: e344.

109. Nabeyama K, Yasunami Y, Toyofuku A et al. Beneficial effects of costimulatory blockade with anti-inducible costimulator antibody in conjunction with CTLA4Ig on prevention of islet xenograft rejection from rat to mouse. Transplantation 2004; 78: 1590-1596.

110. Guillonneau C, Aubry V, Renaudin K et al. Inhibition of chronic rejection and development of tolerogenic T cells after ICOS-ICOSL and CD40-CD40L co-stimulation blockade. Transplantation 2005; 80: 546-554.

111. Chen L, Lu Y, Wang F et al. Expression of co-stimulatory molecule B7-H4 in patients suffering from rheumatoid arthritis. Immunol. Lett. 2013; 154: 25-30.

112. Greenwald RJ, Freeman GJ, Sharpe AH. The B7 family revisited. Annu. Rev. Immunol. 2005; 23: 515-548.

113. Song H, Park G, Kim Y-S et al. B7-H4 reverse signaling induces the apoptosis of EBVtransformed B cells through Fas ligand up-regulation. Cancer Lett. 2008; 266: 227-237. 114. Park GB, Song H, Kim Y-S et al. Cell cycle arrest induced by engagement of B7-H4 on Epstein-Barr virus-positive B-cell lymphoma cell lines. Immunology 2009; 128: 360-368. 115. Xiao ZX, Zheng X, Hu L et al. Immunosuppressive Effect of B7-H4 Pathway in a Murine Systemic Lupus Erythematosus Model. Front Immunol 2017; 8: 1765.

116. Ou D, Wang X, Metzger DL et al. Suppression of Human T-Cell Responses to $\beta$-Cells by Activation of B7-H4 Pathway. Cell Transplant 2006; 15: 399-410.

117. Wang X, Hao J, Metzger DL et al. Local expression of B7-H4 by recombinant adenovirus transduction in mouse islets prolongs allograft survival. Transplantation 2009; 87: 482-490.

118. Wang X, Hao J, Metzger DL et al. Endogenous expression of B7-H4 improves longterm murine islet allograft survival. Transplantation 2013; 95: 94-99.

119. Yamaura $\mathrm{K}$, Watanabe $\mathrm{T}$, Boenisch $\mathrm{O}$ et al. In vivo function of immune inhibitory molecule B7-H4 in alloimmune responses. Am. J. Transplant. 2010; 10: 2355-2362. 120. Nolte MA, Arens R, van Os R et al. Immune activation modulates hematopoiesis through interactions between CD27 and CD70. Nat. Immunol. 2005; 6: 412-418. 121. Kouro T, Medina KL, Oritani K et al. Characteristics of early murine B-lymphocyte precursors and their direct sensitivity to negative regulators. Blood 2001; 97: 2708-2715. 122. Weisel F, Shlomchik M. Memory B Cells of Mice and Humans. Annu. Rev. Immunol. 2017; 35: 255-284.

123. Tarte K, Zhan F, De Vos J et al. Gene expression profiling of plasma cells and plasmablasts: toward a better understanding of the late stages of B-cell differentiation. Blood 2003; 102: 592-600.

124. Arens R, Nolte MA, Tesselaar K et al. Signaling through CD70 regulates B cell activation and IgG production. J. Immunol. 2004; 173: 3901-3908.

125. Jacquot S, Kobata T, Iwata S et al. CD154/CD40 and CD70/CD27 interactions have different and sequential functions in T cell-dependent B cell responses: enhancement of plasma cell differentiation by CD27 signaling. J. Immunol. 1997; 159: 2652-2657. 126. Yamada Y, Ochiai T, Boskovic S et al. Use of CTLA4Ig for Induction of Mixed Chimerism and Renal Allograft Tolerance in Nonhuman Primates: CTLA4Ig for Induction of Mixed Chimerism. American Journal of Transplantation 2014; 14: 2704-2712. 
956

957

958

959

960

961

962

963

964

965

966

967

968

969

970

971

972

973

974

975

976

977

978

979

980

981

982

983

984

985

986

987

988

989

990

991

992

993

994

995

996

997

998

999

1000

1001
127. Sharif A, Shabir S, Chand S et al. Meta-analysis of calcineurin-inhibitor-sparing regimens in kidney transplantation. J. Am. Soc. Nephrol. 2011; 22: 2107-2118.

128. Dai H, Chen J, Shao W et al. Blockade of CD27/CD70 pathway to reduce the generation of memory $\mathrm{T}$ cells and markedly prolong the survival of heart allografts in presensitized mice. Transpl. Immunol. 2011; 24: 195-202.

129. Svachova V, Sekerkova A, Hruba P et al. Dynamic changes of B-cell compartments in kidney transplantation: lack of transitional B cells is associated with allograft rejection. Transpl. Int. 2016; 29: 540-548.

130. Perry DK, Burns JM, Pollinger HS et al. Proteasome inhibition causes apoptosis of normal human plasma cells preventing alloantibody production. Am. J. Transplant. 2009; 9: 201-209.

131. Walsh RC, Alloway RR, Girnita AL et al. Proteasome inhibitor-based therapy for antibody-mediated rejection. Kidney Int. 2012; 81: 1067-1074.

132. Woodle ES, Shields AR, Ejaz NS et al. Prospective iterative trial of proteasome inhibitor-based desensitization. Am. J. Transplant. 2015; 15: 101-118.

133. Trivedi HL, Terasaki PI, Feroz A et al. Clonal deletion with bortezomib followed by low or no maintenance immunosuppression in renal allograft recipients. Transplantation 2010; 90: 221-222.

134. Morrow WR, Frazier EA, Mahle WT et al. Rapid reduction in donor-specific antihuman leukocyte antigen antibodies and reversal of antibody-mediated rejection with bortezomib in pediatric heart transplant patients. Transplantation 2012; 93: 319-324. 135. Eskandary F, Regele H, Baumann L et al. A Randomized Trial of Bortezomib in Late Antibody-Mediated Kidney Transplant Rejection. J. Am. Soc. Nephrol. 2018; 29: 591-605. 136. van de Donk NWCJ, Janmaat ML, Mutis T et al. Monoclonal antibodies targeting CD38 in hematological malignancies and beyond. Immunol. Rev. 2016; 270: 95-112.

137. Lonial S, Weiss BM, Usmani SZ et al. Daratumumab monotherapy in patients with treatment-refractory multiple myeloma (SIRIUS): an open-label, randomised, phase 2 trial. Lancet 2016; 387: 1551-1560.

138. Blankestijn MA, van de Donk NWCJ, Sasser K et al. Could daratumumab be used to treat severe allergy? J. Allergy Clin. Immunol. 2017; 139: 1677-1678.e3.

139. de Leur K, Dor FJMF, Dieterich M et al. IL-21 Receptor Antagonist Inhibits Differentiation of B Cells toward Plasmablasts upon Alloantigen Stimulation. Front Immunol 2017; 8: 306.

140. Petrelli A, Carvello M, Vergani A et al. IL-21 is an antitolerogenic cytokine of the latephase alloimmune response. Diabetes 2011; 60: 3223-3234.

141. Mackay F, Schneider P. Cracking the BAFF code. Nat. Rev. Immunol. 2009; 9: 491502.

142. Schneider P, MacKay F, Steiner V et al. BAFF, a novel ligand of the tumor necrosis factor family, stimulates B cell growth. J. Exp. Med. 1999; 189: 1747-1756.

143. Moore PA, Belvedere 0, Orr A et al. BLyS: member of the tumor necrosis factor family and B lymphocyte stimulator. Science 1999; 285: 260-263.

144. Wallweber HJA, Compaan DM, Starovasnik MA et al. The crystal structure of a proliferation-inducing ligand, APRIL. J. Mol. Biol. 2004; 343: 283-290.

145. Thompson JS, Bixler SA, Qian F et al. BAFF-R, a newly identified TNF receptor that specifically interacts with BAFF. Science 2001; 293: 2108-2111.

146. Pers J-0, Daridon C, Devauchelle V et al. BAFF overexpression is associated with 
1002 autoantibody production in autoimmune diseases. Ann. N. Y. Acad. Sci. 2005; 1050: 34-39.

1003 147. Stohl W. Therapeutic targeting of the BAFF/APRIL axis in systemic lupus

1004 erythematosus. Expert Opin. Ther. Targets 2014; 18: 473-489.

1005 148. Hunter CA, Jones SA. IL-6 as a keystone cytokine in health and disease. Nat. Immunol.

1006 2015; 16: 448-457.

149. Jordan SC, Choi J, Kim I et al. Interleukin-6, A Cytokine Critical to Mediation of

1008

1009

Inflammation, Autoimmunity and Allograft Rejection: Therapeutic Implications of IL-6

1010 Receptor Blockade. Transplantation 2017; 101: 32-44.

1011 150. Shulman Z, Gitlin AD, Weinstein JS et al. Dynamic signaling by T follicular helper cells

1012

1013 during germinal center B cell selection. Science 2014; 345: 1058-1062.

151. Gabay C, Emery P, van Vollenhoven R et al. Tocilizumab monotherapy versus adalimumab monotherapy for treatment of rheumatoid arthritis (ADACTA): a

1014 randomised, double-blind, controlled phase 4 trial. Lancet 2013; 381: 1541-1550. 152. Jones SA, Scheller J, Rose-John S. Therapeutic strategies for the clinical blockade of IL-6/gp130 signaling. J. Clin. Invest. 2011; 121: 3375-3383.

1018 153. Vo AA, Choi J, Kim I et al. A Phase I/II Trial of the Interleukin-6 Receptor-Specific Humanized Monoclonal (Tocilizumab) + Intravenous Immunoglobulin in Difficult to Desensitize Patients. Transplantation 2015; 99: 2356-2363.

1020

1021 154. Shen H, Goldstein DR. IL-6 and TNF-alpha synergistically inhibit allograft acceptance. J. Am. Soc. Nephrol. 2009; 20: 1032-1040.

1022 155. Zhao X, Boenisch O, Yeung M et al. Critical role of proinflammatory cytokine IL-6 in allograft rejection and tolerance. Am. J. Transplant. 2012; 12: 90-101.

1025

Figure legends

1032 Figure1 : Cellular mechanisms involved in antibody mediated rejection.

1033 Antigen recognition initiates priming of $T$ cells and $B$ cells. $T$ cells begin to differentiate into

1034 Tfh as they move to the $T$ cell zone $B$ cell follicle border, where cognate $T$-B interactions

1035 lead to the development of the germinal center. Two zones can be anatomically observed, 1036 the dark zone where B cells proliferate very rapidly and the light zone where Tfh $B$ cell 1037 interactions are thought to primarily take place. Affinity maturation occurs in the GC in a 1038 cyclical manner alternating between mutating the BCR and acquiring Tfh help. Throughout 1039 this process, memory B cells and long-lived plasma cells are formed. DSA: Donor-specific 1040 antibody; Ag: antigen; DC: dendritic cells; DZ: Dark Zone; GC: germinal center; LZ: light 1041 zone; Tfh: T follicular helper cells 


\section{Figure 2: Co-stimulatory molecules}

1044 A: Co-stimulatory molecules expression and interaction patterns between Tfh and B cell 1045 are shown to illustrate the complexity of their interactions. Red molecules indicate TNFa 1046 family members, and blue molecules are B7 family members. Green arrows indicate 1047 stimulatory interactions and red indicate inhibitory interactions. Some drugs, which target 1048 these interactions, are also shown. B: Key molecules of the GC Tfh B cell interactions are 1049 depicted. An emphasis is made on the timing of expression of these molecules through the 1050 different stages of $B$ cell differentiation leading to DSA production. MHC: Major 1051 histocompatibility complex-II; CTLA-4: cytotoxic T lymphocyte antigen 4; BCR: B cell 1052 receptor; ICOS: inducible T cell costimulator ; ICOS-L: ICOS ligand; PD-1: program death 1053 1; PD-L: PD-1 ligand

\section{Figure 3: Immunosuppressant agents and classes in kidney Transplantation}

1058 This diagram is a summary of our discussion of the potential therapeutic targets and 1059 their effects on different cells key to humoral responses. New data show that co-stim 1060 blockade targets multiple stages of cell-cell interactions. In contrast to Tfh-B cells 1061 interactions, relative few drugs target plasma cells. Furthermore, bortezomib and anti1062 CD38, which do affect plasma cells actually have much broader effects. Therapeutic 1063 compounds are depicted in red font. APC: antigen presenting cell; BCR: B cell 1064 receptor; CoB : Co-stimulatory blockade; IL: interleukin; MHC: Major 1065 histocompatibility complex; TCR: T cell receptor; 

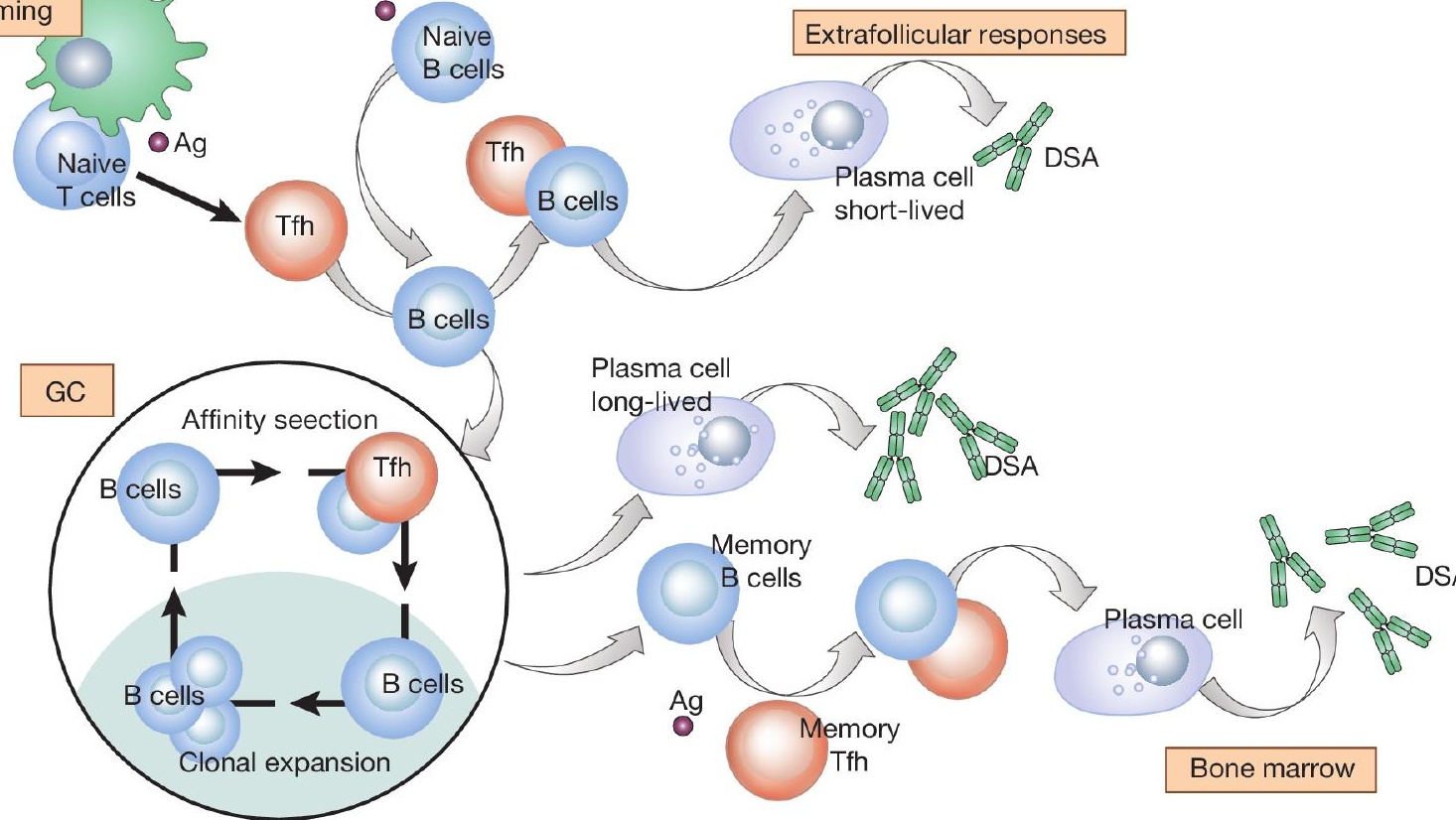


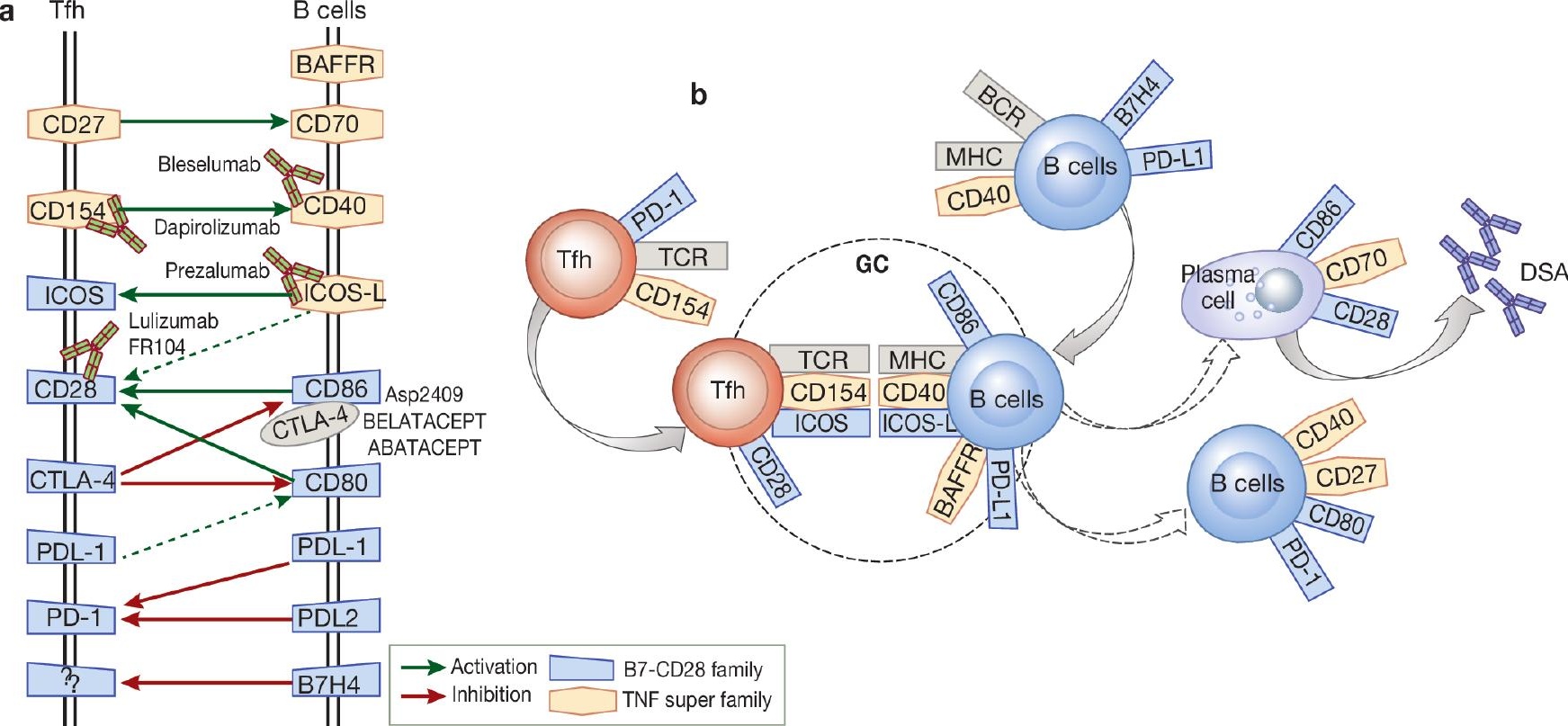




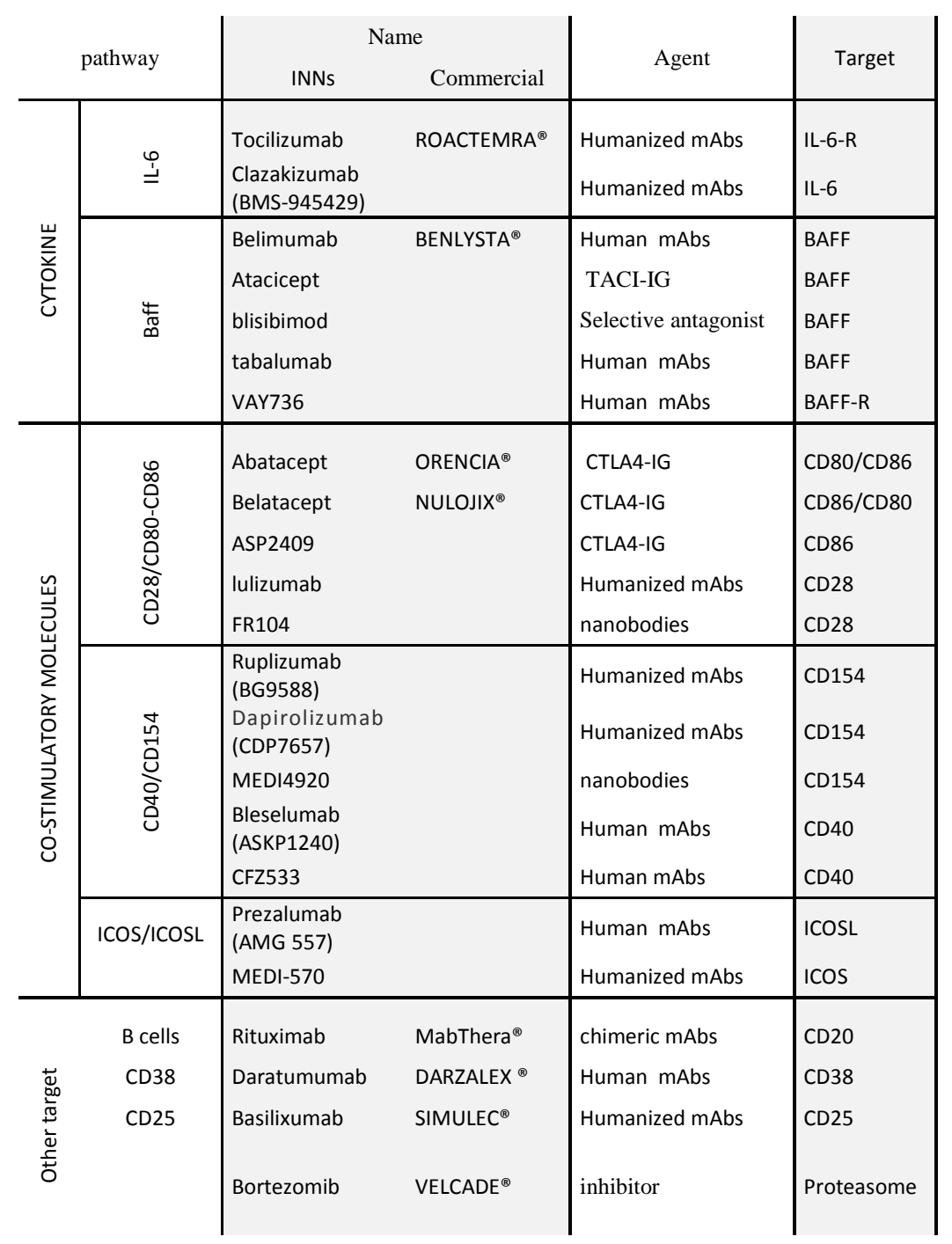

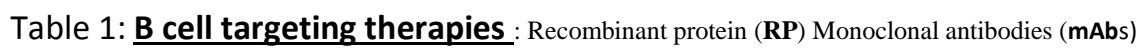

